\title{
Developing Nursing Management Protocol for Maternity Nurses Regarding Emergency Obstetric Care
}

\author{
Eman Mohammed Abdelhakm, Amira Refaat Said* \\ Faculty of Nursing, Benha University, Benha, Egypt \\ Email address: \\ Amira.refaat21@yahoo.com (A. R. Said) \\ ${ }^{*}$ Corresponding author \\ To cite this article: \\ Eman Mohammed Abdelhakm, Amira Refaat Said. Developing Nursing Management Protocol for Maternity Nurses Regarding Emergency \\ Obstetric Care. American Journal of Nursing Science. Vol. 6, No. 5, 2017, pp. 418-425. doi: 10.11648/j.ajns.20170605.16
}

Received: August 19, 2017; Accepted: September 4, 2017; Published: October 11, 2017

\begin{abstract}
The aim of the study was to develop nursing management protocol for maternity nurses regarding obstetric emergencies. An intervention (quasi experimental) study design was used. The study was conducted in the Obstetrics and Gynecology Emergencies Department at Benha University Hospital. A convenient sample of all nurses working in Obstetrics and Gynecology emergencies department at Benha University Hospital (40 nurse). Two tools were used for data collection; I) A structured interviewing questionnaire: include two parts; Part 1: Socio demographic characteristics of the study nurses: included (Age, educational level, years of experience, previous training program). Part 2: Assessment of nurses' knowledge regarding obstetric emergencies such as definition, causes, basic priorities and preparations for emergency obstetrics care. II) Observational checklist for evaluating nursing management regarding obstetric emergencies such as resuscitation, nursing management of preeclampsia, eclampsia, infection, trauma \& shock and assessment of fetal wellbeing. The study results showed that $88.7 \%$ of nurses had poor knowledge before intervention of the protocol. However, $75.7 \%$ of them had good knowledge after intervention respectively. As well as, $77.5 \%$ of them had unsatisfactory practices toward emergency obstetrics care before intervention of the protocol. Meanwhile, after intervention $82.3 \%$ had satisfactory practices respectively. The study concluded that Nurses' management protocol has appositive effect on nurse's knowledge and practices regarding obstetric emergencies. There was a highly statistically significant difference before / after protocol of the studied nurses' knowledge and practice regarding obstetrics emergencies $(\mathrm{P} \leq 0.001)$. The study recommended that Simple guidelines regarding emergency obstetrical nursing care can be attributed to nurses in the emergency obstetrics department. Continuous refreshment courses and follows up programs for nurses regarding emergency obstetrics care.
\end{abstract}

Keywords: Emergency Obstetrics Care, Nursing Management Protocol

\section{Introduction}

Obstetrical emergencies are life threatening medical condition that occurs during pregnancy, labor, or the postpartum period. Globally, every year an estimated 287,000 women die of complications during pregnancy or childbirth There are a variety of obstetrical emergencies of pregnancy that can threaten the well-being of both mother and child. The five major global causes of maternal death are severe bleeding; infections, unsafe induced abortion, hypertensive disorders of pregnancy (eclampsia) and obstructed labor yet many of these deaths are preventable [16].

The world health organization posits the following conditions as obstetrical emergencies, ectopic or tubal pregnancy, abruptio placenta, placenta previa, sever preeclampsia \& eclampsia or pregnancy induced hypertension, premature rupture of membranes, amniotic fluid embolism, inversion or rupture of uterus, placenta accreta, prolapsed umbilical cord, shoulder dystocia, postpartum hemorrhage and postpartum infection [23].

Obstetrical emergencies are the leading causes of maternal mortality worldwide particularly in developing countries where lack of transport facilities, financial constraints due to poverty, illiteracy, ignorance, inadequate health infrastructure and meager blood bank facilities. Although most of obstetrical emergency situations have been well described and have widely accepted management strategies, the reports 
of maternal mortality continue to highlight wide spread and substandard care of obstetrical emergencies probably contributed to mortality reports [9].

Obstetrics emergency protocols are strategies geared towards reducing maternal deaths. The core elements of obstetrics emergency protocols include availability of skilled personnel to carry out effective interventions during pregnancy, delivery and postnatal period, availability of essential drugs and supplies and patient referrals. Skilled health professionals working in favorable environment should be available and able to attend to every pregnancy, delivery and must be available 24 hours a day, seven days a week [6].

The goals of nursing management protocol of critically ill obstetric women involve intensive monitoring and physiologic support for women with life-threatening to detect abnormal findings or subtle signs and symptoms of developing complications. Thus, the nursing contribution is very important to the rescue and mobilization of the team process to provide proper immediate care for the mother and the newborn and prevent any complication to be arises [4].

Nurses have a crucial role in the care of the woman during pregnancy and childbirth in the obstetric department being considers the first members of the healthcare team to detect abnormal findings or subtle signs and symptoms to provide proper immediate care for the pregnant woman $\&$ her fetus to prevent any complication to be arises so, it important to have be knowledgeable a well-trained nurse about the normal and abnormal processes of child birth appropriate technical skills; communicate and collaborate well with the health care team, self-confidence and possess the necessary judgment, skills to cope with stressful and emergency conditions [17].

\subsection{Significance of the Study}

Obstetrical emergencies can occur at any time in the birthing process; therefore all health professionals involved in caring for women should be competent in both accurate diagnosing and appropriate and timely management of an obstetrical emergency. An obstetrical emergency therefore requires an immediate and appropriate response to prevent complications that may affect not only the childbearing woman [13].

Every day around the world, approximately 830 women die from preventable causes related to pregnancy and childbirth. The maternal mortality ratio in developing countries in 2015 is 239 per 100000 live births versus 12 per 100000 live births in developed countries. Integrated care before, during and after childbirth can save the lives of women and newborn babies. Between 2016 and 2030, as part of the Sustainable Development Goals, the target is to reduce the global maternal mortality ratio to less than 70 per 100000 live births [24].

In Egypt the maternal mortality ratio was 33 deaths/100,000 live births [21]. In order to assist nurses to be competent in delivering care for high risk women, Developing nursing management protocol was applied for nurses to update and upgrade their knowledge, skills and to be reference guide whenever needed, also, it should be utilized and integrated through educational modalities, therefore this study was conducted.

\subsection{Aim of the Study}

This study was aimed to develop nursing management protocol for maternity nurses regarding obstetric emergencies. This aim was achieved through:

1. Assessing nurses' knowledge and practices regarding obstetric emergencies.

2. Designing and implement nursing management protocol regarding obstetric emergencies.

3. Evaluating nursing management protocol after application regarding obstetric emergencies.

\subsection{Research Hypothesis}

Nurses' management protocol has appositive effect on nurse's knowledge and practices regarding obstetric emergencies.

\section{Subjects and Methods}

\subsection{Research Design}

Quasi experimental design was used for conducting the study.

\subsection{Setting}

The study was conducted at Benha University Hospital in Obstetrics and Gynecology Emergencies Department.

\subsection{Subjects}

\subsubsection{Subject Type}

A convenient sample of a total nurse's works in Obstetrics and Gynecology emergencies department at Benha University Hospital were recruited for the study (40 nurses).

\subsubsection{Subject Size}

Size of the sample was completed during 6 months /three days per week, all nurses who worked at previous mentioned setting.

\subsection{Tools of Data Collection}

Two tools were utilized for data collection, prepared by the researchers after reviewing related literature and tested by a panel of experts for validity.

\subsubsection{First Tool}

A structured interviewing questionnaire: include two parts; Part 1: Socio demographic characteristics of the study nurses: included (Age, educational level, years of experience, previous training program). Part 2: Assessment of nurses' knowledge regarding obstetric emergencies which includes (definition, causes, basic priorities and preparations for emergency obstetrics care- causes of bleeding during pregnancy, labor \& post natal- priorities of nursing care for bleeding- causes, signs $\&$ symptoms of maternal infection and priorities of nursing care for infection- priorities of nursing care for external trauma- priorities of nursing care for toxemia.

Scoring system:

The questions were scored as the following; score (1) was given for the correct answer and (0) for the incorrect answer 
before and after application of the protocol. The scores of total knowledge was considered as more than $60 \%$ was adequate and less than $60 \%$ was in adequate.

\subsubsection{Second Tool}

Observational checklist: it was adapted from the (Royal College of Obstetricians and Gynecologists guidelines, 2016) guidelines present recognized methods and techniques for clinical practice, based on published evidence for management of obstetric emergency situations to evaluate nursing practices regarding obstetric emergencies which includes basic nursing care in obstetrics emergency such as resuscitation ( air way, oxygen administration, breathing and circulation) - nursing management of preeclampsia, eclampsia, infection, trauma and shock- assessment of fetal wellbeing- Perineal care- catheter care - partial path.

Scoring system:

The checklist items were scored (2) for done each step correctly while (1) score was given for done incomplete correctly and (zero) score for not done. The scores of total practice were considered as $\geq 80 \%$ was satisfactory and $\leq$ $80 \%$ was unsatisfactory.

\subsection{Methods}

The study was executed according to the following steps

\subsubsection{Approvals}

A written official approval to conduct this research was obtained from the director of Benha University hospital that was taken and delivered to the director of the Obstetrics and Gynecology Emergencies Department, in order to obtain their agreement to conduct the study after explaining its purpose.

\subsubsection{Tools Validity and Reliability}

The developed tool was reviewed for appropriateness of items and measuring the concepts through five an expert jury panel in the field of maternity nursing and obstetric medicine specialty to assure content validity. The questionnaires were modified according to the panel judgment on clarity of sentences and appropriateness of content (The reliability was done by Cronbach's Alpha coefficient test equal 0.87).

\subsubsection{Ethical Considerations}

All ethical issues were assured, participants were given explanations about the purpose of the study, and they were also informed that they could withdraw from the study at any time before the completion of the study. Participants who agreed to complete in this study were asked to sign a consent form. Confidentiality of participants ${ }^{\text {ee }}$ information was assured and the data were accessed only by the investigators involved in the study.

\subsubsection{The Pilot Study}

The pilot study was conducted on 4 nurses $(10 \%$ of 40 nurses) to test the clarity and the applicability of the tool, find out the possible obstacles and problems that might face the researchers and interfere with data collection. The study sample included in the pilot study was included also into the study due to no modification done in the tool.

\subsubsection{Procedures}

Incorporate the following phases as following

1) Assessment phase:

Nurses were assessed for their needs prior implementation of the nursing management protocol regarding obstetric emergencies care.

2) Planning phase:

The content of the nursing management protocol related to obstetric emergencies was designed to meet the following objectives:

a) General objective:

At the end of nursing management protocol sessions each nurse should be able to acquire essential knowledge and skills needed to provide competent care to women with obstetric emergencies.

b) Specific objectives

At the end of protocols sessions each nurse should be able to:

1. Define emergencies in obstetrics.

2. List and discuss causes of emergencies in obstetrics.

3. Give priorities of nursing care for obstetric emergencies.

4. Apply preparations needed for emergency obstetric care.

5. Discuss causes of bleeding in obstetrics.

6. Determine priorities of nursing care for bleeding in obstetrics

7. Apply the nursing care for trauma in obstetrics

8. Explain causes, signs and symptoms of infection in obstetrics

9. Determine priorities of nursing care for infection in obstetrics

10. Recognize priorities of nursing care for toxemia during pregnancy in obstetrics

As well as the nurses should be able to practice proficiently all procedures related to obstetric emergency situations.

Implementation phase: The nursing management protocol was carried out at Obstetrical and Gynecological Emergency Department at Benha University Hospital. Based on the results obtained from pre training assessment using the interviewing questionnaire and observation checklists, teaching and training were constructed to satisfy the studied nurses' deficit knowledge and practice about obstetrics emergencies care. Implementation of teaching and training took (12) weeks period and were implemented for a group of (4) nurses according to working circumstances, nurses' physical and mental readiness. The researcher visited the setting three days per week. The overall sessions were 8 sessions were devoted to ( 3 theory and 5 practical), nurses were divided into 10 groups and the content was implemented for each group separately. The duration of each theory session was ranged from 20-30 minutes while practical session was ranged from 30-60 minutes including periods of discussion according to their achievement, progress and feedback. The researchers went to the unit two 
days per week from 9.00 A.M to 1.00 P.M for six months starting from the beginning of June 2016 till end of November 2016. At the beginning of first session an orientation to the program, general and specific objectives were explained. Arabic languish was used to suit all level of education. Different methods of teaching and training strategies were used such as lecture, group discussion, demonstration and re-demonstration for clinical procedures Instructional media included, handout prepared by the researcher and distributed to all nurses in the first day of the training. After each session feedback was done. Most nurses were cooperating and interested by the topic.

3) Evaluation phase:

After completion of the protocol sessions the questionnaire format and observation sheet were filled again to evaluate effectiveness of the protocol with the same pretest questionnaire.

\subsubsection{Statistical Analysis}

Data was collected, presented in tabular form. Percentages were calculated for qualitative data and $\mathrm{x} 2$ for test of significance, mean and standard deviations were calculated for quantitative data using the Statistical Package for Social Sciences (SPSS version 20) for statistical analysis.

\section{Results}

Table (1) shows that, $47.5 \%$ of studied sample were over 30 years, the mean age was $29.5 \pm 6.7$. Regarding qualification, most of them $77.5 \%$ had secondary school diploma and only $5.0 \%$ had bachelor degree. As regards years of experience, more than half of them $60.0 \%$ had more than ten years of experience, while $17.5 \%$ had less than 5 years of experience, the mean years of experience $11.5 \pm 6.4$. The majority of the studied nurses $87.5 \%$ did not receive any training program regarding obstetric emergencies in the department.

Table (2) shows that, there was a highly statistically significant difference before and after protocol regarding the studied nurses' knowledge.

Figure (1) Illustrates that, $(88.75 \%)$ of studied nurses have inadequate knowledge before protocol compared to (75.75\%) after protocol have adequate knowledge respectively.

Table (3) clears that; there was highly statistically significant difference before / after training protocol during emergency situations in obstetrics procedures.

Table (4) shows that, there was positive statistically significant correlation between knowledge and age before \& after protocol. Also, there was positive statistically significant correlation between knowledge and years of experience before \& after protocol.

Table (5) shows that, there was positive statistically significant correlation between practice and age before and after training. Moreover, there was positive statistically significant correlation between practice and years of experience before and after training.

Table (6) reveals that, there was no statistically significant correlation between knowledge before teaching and practice before training. On the other hand, there was statistically significant correlation between knowledge after teaching and practice after training.

Figure (2) Illustrates that (77.5\%) of studied nurses have unsatisfactory practice before protocol compared to $(82.3 \%)$ after protocol have satisfactory practice respectively.

Table 1. Distribution of the studied nurses according to their socio demographic characteristics $(n=40)$.

\begin{tabular}{lll}
\hline \multirow{2}{*}{ Characteristics of nurses } & $\mathbf{n}=\mathbf{4 0}$ \\
\cline { 2 - 3 } & $\mathbf{N u m b e r}$ & Percent \\
\hline Age ( years) & 5 & \\
$<20$ & 7 & 12.5 \\
$20-$ & 9 & 17.5 \\
$25-$ & 19 & 22.5 \\
$\geq 30$ & $29.5 \pm 6.7$ & 47.5 \\
Mean \pm SD & & \\
Educational qualification & 31 & 77.5 \\
Secondary school diploma & 7 & 17.5 \\
Technical institution & 2 & 5.0 \\
Bachelor degree & & \\
Experience (years) & 7 & 17.5 \\
$<5$ & 9 & 22.5 \\
$5-10$ & 24 & 60.0 \\
$>10$ & $11.5 \pm 6.4$ & \\
Mean \pm SD & \multicolumn{2}{|l}{} \\
Training about emergency obstetric care courses & 5 & 12.5 \\
Yes & 35 & 87.5 \\
No & &
\end{tabular}

Table 2. Distribution of the studied nurses' regarding their knowledge about obstetrics emergencies in obstetric department before / after protocol ( $n=40)$.

\begin{tabular}{|c|c|c|c|c|c|c|c|c|c|c|}
\hline \multirow{3}{*}{ Obstetric Emergencies } & \multirow{2}{*}{\multicolumn{2}{|c|}{$\begin{array}{l}\text { Before program } \\
\text { correct answer }\end{array}$}} & & & \multicolumn{4}{|c|}{ After program } & \multirow{3}{*}{$\begin{array}{l}X 2 \\
\text { test }\end{array}$} & \multirow{3}{*}{ p-Value } \\
\hline & & & \multicolumn{2}{|c|}{ Incorrect answer } & \multicolumn{2}{|c|}{ correct answer } & \multicolumn{2}{|c|}{ Incorrect answer } & & \\
\hline & No & $\%$ & No & $\%$ & No & $\%$ & No & $\%$ & & \\
\hline Definition of obstetric emergencies & 11 & 27.5 & 29 & 72.5 & 28 & 70 & 12 & 30 & 31.2 & $<0.001 * *$ \\
\hline Causes of obstetric emergencies. & 8 & 20 & 32 & 80 & 24 & 60 & 16 & 40 & 42.7 & $<0.001 * *$ \\
\hline Basic Priorities \& Preparations needed & 18 & 45 & 22 & 55 & 28 & 70 & 12 & 30 & 13.8 & $<0.001 * *$ \\
\hline Causes of bleeding & 9 & 22.5 & 31 & 77.5 & 33 & 82.5 & 7 & 17.5 & 56.6 & $<0.001 * *$ \\
\hline Priorities of nursing care for bleeding & 12 & 30 & 28 & 70 & 31 & 77.5 & 9 & 22.5 & 45.5 & $<0.001 * *$ \\
\hline Causes of infection & 2 & 5 & 38 & 95 & 33 & 82.5 & 7 & 17.5 & 64.2 & $<0.001 * *$ \\
\hline Signs and symptoms of infection & 7 & 17.5 & 33 & 82.5 & 28 & 70 & 12 & 30 & 96.6 & $<0.001 * *$ \\
\hline Priorities of nursing care for infection & 5 & 12.5 & 35 & 87.5 & 25 & 62.5 & 15 & 37.5 & 40.1 & $<0.001 * *$ \\
\hline Priorities of nursing care for trauma & 12 & 30 & 28 & 70 & 21 & 52.5 & 19 & 47.5 & 34.1 & $<0.001 * *$ \\
\hline $\begin{array}{l}\text { Priorities of nursing care for toxaemia } \\
\text { during pregnancy }\end{array}$ & 7 & 17.5 & 33 & 82.5 & 39 & 97.5 & 1 & 2.5 & 101.1 & $<0.001^{* *}$ \\
\hline
\end{tabular}

** A highly statistical significant difference $(\mathrm{P} \leq 0.001)$ 
Table 3. Distribution of the studied nurses' regarding practices about obstetric emergencies in obstetric department before / after management protocol $(n=40)$.

\begin{tabular}{|c|c|c|c|c|c|c|c|c|c|c|}
\hline \multirow{3}{*}{ Items } & \multicolumn{4}{|c|}{ Before management protocol } & \multicolumn{4}{|c|}{ After management protocol } & \multirow{3}{*}{$\begin{array}{l}\text { X2 } \\
\text { test }\end{array}$} & \multirow{3}{*}{ p-Value } \\
\hline & \multicolumn{2}{|c|}{$\begin{array}{l}\text { Complete } \\
\text { Correct }\end{array}$} & \multicolumn{2}{|c|}{$\begin{array}{l}\text { Incomplete Correct } \\
\text { \& Incorrect }\end{array}$} & \multicolumn{2}{|c|}{$\begin{array}{l}\text { Complete } \\
\text { Correct }\end{array}$} & \multicolumn{2}{|c|}{$\begin{array}{l}\text { Incomplete Correct } \\
\text { \& Incorrect }\end{array}$} & & \\
\hline & No & $\%$ & No & $\%$ & No & $\%$ & No & $\%$ & & \\
\hline $\begin{array}{l}\text { Basic nursing care (ABCs of resuscitation: airway, } \\
\text { oxygen admin. breathing, and circulation ) }\end{array}$ & 10 & 25 & 30 & 75 & 29 & 72.5 & 11 & 27.5 & 10 & $<0.001 * *$ \\
\hline Management of bleeding & 6 & 15 & 34 & 85 & 31 & 77.5 & 9 & 22.5 & 35.6 & $<0.001^{* *}$ \\
\hline Management of preeclampsia and eclampsia & 10 & 25 & 30 & 75 & 36 & 90 & 4 & 10 & 65.2 & $<0.001 * *$ \\
\hline Infection control measures & 4 & 10 & 36 & 90 & 26 & 65 & 14 & 35 & 45.9 & $<0.005^{*}$ \\
\hline Management of trauma & 6 & 15 & 34 & 85 & 34 & 85 & 6 & 15 & 55.3 & $<0.001 * *$ \\
\hline Management of shock & 10 & 25 & 30 & 75 & 37 & 92.5 & 3 & 7.5 & 56.5 & $<0.001 * *$ \\
\hline Assessment of the fetal wellbeing & 4 & 10 & 36 & 90 & 35 & 87.5 & 5 & 12.5 & 35.8 & $<0.001 * *$ \\
\hline Perineal care & 12 & 30 & 28 & 70 & 36 & 90 & 4 & 10 & 37.8 & $<0.001^{* *}$ \\
\hline Catheter care & 12 & 30 & 28 & 70 & 30 & 75 & 10 & 25 & 29.6 & $<0.001 * *$ \\
\hline Partial bath & 10 & 25 & 30 & 75 & 38 & 95 & 2 & 5 & 45.6 & $<0.001 * *$ \\
\hline
\end{tabular}

*A statistical significant difference $(\mathrm{P} \leq 0.05)$

$* *$ A highly statistical significant difference $(\mathrm{P} \leq 0.001)$

Table 4. Correlation coefficient between total nurses' knowledge scores regarding emergency obstetric care before lafter protocol, age and years of experience.

\begin{tabular}{lllll}
\hline \multicolumn{4}{l}{ Total knowledge } \\
\hline Variable & Pre & & Post & \\
\hline & R & P & R & P \\
\hline Age & 0.531 & $<0.01$ & 0.635 & $<0.01$ \\
Years of experience & 0.528 & $<0.01$ & 0.636 & $<0.01$ \\
\hline
\end{tabular}

Table 5. Correlation coefficient between total nurses' practices scores regarding emergency obstetric care before / after training, age and years of experience.

\begin{tabular}{lllll}
\hline & \multicolumn{4}{l}{ Total knowledge } \\
\hline Variable & Pre & & Post & \\
\hline & R & P & R & P \\
\hline Age & $<0.01$ & 0.692 & $<0.01$ & 0.436 \\
Years of experience & $<0.01$ & 0.635 & $<0.01$ & 0.421 \\
\hline
\end{tabular}

Table 6. Correlation coefficient between total scores of nurses' Knowledge and practice before / after protocol.

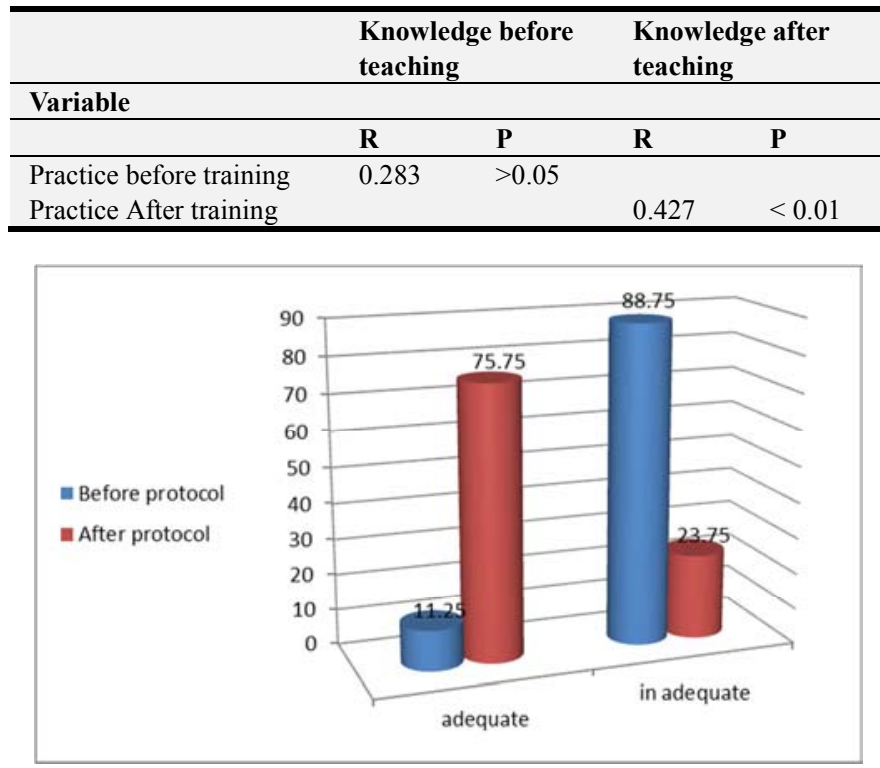

Figure 1. Percentage distribution of the studied nurses in relation to their total knowledge score prel post program.

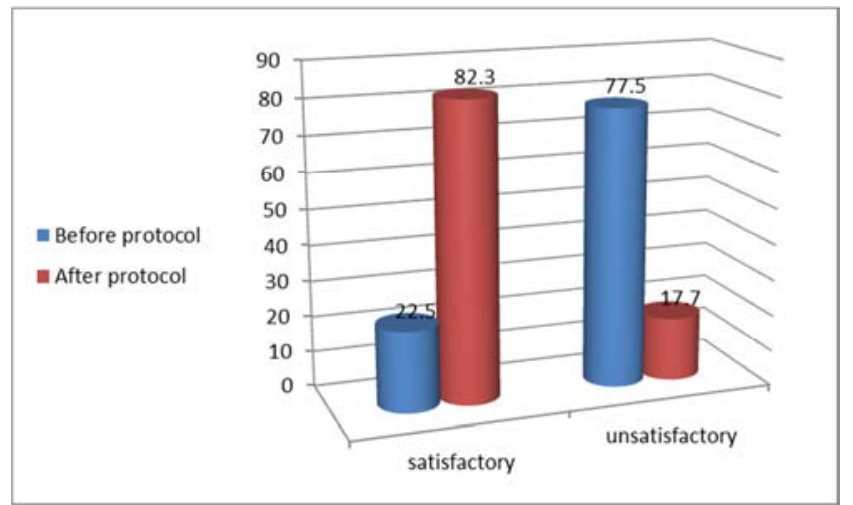

Figure 2. Percentage distribution of the studied nurse's regarding total nursing practices pre/ post training program.

\section{Discussion}

Developing protocols regarding obstetric emergencies is essential to provide the highest quality and most costefficient nursing care. To advance quality of care provided by nurses, increase satisfaction of women. The quality of obstetric emergencies and new-born care services are very important, particularly in countries with a high burden of maternal and new-born mortality, appropriate care when emergencies arise according to accepted clinical standards and protocol, providing services in a manner corresponding to the rights and needs of all clients which include continuity of care, information and informed choice, privacy and confidentiality, dignity, comfort and expression of opinion Otolorin et al. [19].

This study was aimed to develop protocol for nurses regarding obstetric emergencies in obstetrical and gynecological emergency department at Benha University Hospital. This aim was achieved through assessing nurses' knowledge \& practices regarding obstetrics emergencies, design \& implements training protocols \& evaluates nurses' knowledge and practical skills after nursing management protocol application regarding obstetric emergencies.

Regarding characteristic of the studied nurses, the study 
showed that, near to half of studied sample were over 30 years. Most of nurses had secondary school diploma. More than half of the nurses had more than ten years of experience. Majority of the studied nurses did not receive any training program regarding management of obstetric emergency situations.

This interpretation is in the same line with the finding of Islam et al, [14]. who studied "The Implementation of Emergency Obstetrics Care Training in Bangladesh". This study found that the majority of nurses who were included in the study had diploma nurse that were graduated since long period of time and did not attend any refreshing courses that affected negatively on the quality of obstetrics care. Also, this finding agrees with Attia. [3]. who found that about two third of the nurses expressed that there is no protocol related to obstetrical emergency nursing care that reflect on their performance.

Regarding nurses' knowledge about obstetrical emergencies in obstetric and gynecological emergency department, results of the present study revealed that there was more than half of the nurses included in the study had incorrect knowledge regarding obstetrical emergencies that negatively reflected upon the nursing care offered for the admitted cases with obstetrical emergencies. This result may be due to absence of educational program regarding emergency situations in the unit. Also, this lack of knowledge may be related to the level of education and could be interpreted that nearly most of the studied nurses were diploma nursing graduate that were graduated since long period of time that might led them to lose too much of their basic graduation knowledge and skills, as well as absence of training programs related to obstetrical emergencies care.

This result is congruent with El-Bahy et al., [12]. Who studied “Effect of Educational Program for Nurses about Pregnancy Induced Hypertension on their Knowledge in Port Said, Hospitals, Faculty of Nursing, Cairo University". This study found that the nurses had incorrect knowledge about nursing care for preeclampsia and eclampsia. This may be due to the fact that nurses did not receive adequate information or may need for refreshing in-services training regarding management of pre-eclampsia and eclampsia during labor.

The results of the present study revealed also that there was significant improvement of nurses' knowledge after protocols application compared to before it. This finding was agreement with Brenner., et al [8]. who reported that, training health-care providers in obstetric emergency and newborn care concentrate the need to build the capacity of health-care providers to recognize and manage complications during pregnancy, labor and the post-partum period through providing skills and competency-based training in skilled birth attendance, emergency obstetric care and early newborn care which considered an approach that was successful in improving skills \& improved availability and quality of care.

This result is contradicted with Bayley et al, [5]. Who concluded that training had little impact on levels of knowledge and the gap of knowledge couldn't be overcome by simply providing more training, so most of staff reported perception of poor quality of care.

Regarding practical skills of nurses during emergency situations in obstetrics, results of the present study revealed that, nearly three quarters of the studied nurses had incorrect practice regarding management of obstetrical emergencies in the unit before protocols implementation. This could be explained by their lack of knowledge regarding management of obstetrical emergencies, absence of protocol related to emergency obstetric care and lack of training programs.

This unsatisfactory level of practice showed the importance of continuous education, protocols and regular updating clinical courses for nurses to promote knowledge and practice. Therefore, it is important and essential that nurses are well trained and educated on obstetrical emergencies especially in the emergency department as they have the vital role to play to inform the doctor and begin the initial assessment and management of such cases.

The present study revealed improvement in nurses' practice after nursing management protocol. This is supported by Traoré et al., [22]. Who mentioned, there was a relation between the availability of guidelines for the management of obstetrical emergencies and the higher competency of physicians, health technicians, and obstetric nurses $(\mathrm{P}<0.001)$.

This result is supported by Islam et al., [14]. Who indicated that regular training of nursing personnel will improve and enhance quality of health care. Also, this result agrees with El-Bahy et al., [12]. Who stated that, the majority of nurses before training had incorrect practice regarding basic care for women with pregnancy induced hypertension and concentrate that partial care \& perineal care are also important components of health care for women during pregnancy and should not be neglected. Bradley et al., [7], found that inadequate obstetric skills, undermining performance and professionalism were main factors that effect on the quality of care.

In addition to Alderman, [2], reported that effective communication between nurses and other members of the health care team is an essential component of patient safety. Furthermore Alam et al., [1] who found that the main reason for non-availability of obstetric emergency care services was the lack of specialists and trained nursing providers. And also, this result agrees with Chodzaza \& Bultemeier, [10] who found that there were facility/ staff themes which emerged as contributing to the poor care and included inadequate resources, inadequate staffing, poor teamwork, and inadequate knowledge.

Results of the present study revealed that there was positive statistically significant correlation between knowledge before and after training in age and years of experience, this result is disagree with Kavitha et al., [15] who found that there was no significant relation between nurses 'knowledge regarding emergency obstetric management and their age.

Also, results of the present study revealed that there was 
positive statistically significant correlation between practice and age before \& after training. Moreover, there was positive statistically significant correlation between practices before $\&$ after nursing management protocol and years of experience. This result disagrees with Attia [3] who found that there was no statistically significant relation between nurses' performance \& their age. Also, this result agrees with Delucia et al. [11] who studied Performance in nursing found that work experience influence nurses' performance.

Regarding correlation between total scores of nurses' knowledge, practice before \& after nursing management protocol. There was statistically significant correlation. This finding is agreed with Chodzaza \& Bultemeier [10], who reported that, there was highly statistically significant between nurses' practice and their knowledge. Ominyi\& Nwodom [18]. Who concluded that there was a highly statistically significant between nurses' perception and practice of evidence-based practice in federal teaching hospital abakaliki.

Generally, this study pointed out that, after nursing management protocol, there was improvement in the most aspects of knowledge and practices, this partially supported the study hypothesis, and it revealed the areas of weakness of nursing practices. Moreover, it is hoped to establish inservices training programs, standards of care and follow up for continuing improving knowledge and practices.

\section{Conclusion}

Nurses' management protocol has appositive effect on nurse's knowledge and practices regarding obstetric emergencies. There was a significant improvement in the nurses 'knowledge and some aspects of practice regarding obstetric emergencies situation after nursing management protocol implementation compared with that before it. There was positive correlation between nurses' knowledge and their practice before and after protocol in relation to their age and years of experience and positive significant correlation between nurses' knowledge and practice after protocol. Nurses' knowledge and practice about obstetric emergency situations improved after nursing management protocol application.

\section{Recommendations}

In the light of the findings of current study the following recommendations were be suggested:

a. Simple guidelines regarding obstetrical emergency nursing care must be available at the Emergency Obstetrics Department.

b. Developing periodical training and teaching programs regarding obstetrical emergency nursing care.

c. Continuous refreshment courses and follows up programs.

d. Replication of the study on large sample size and in different hospitals to evaluate knowledge and practices of nurses in relation to obstetrical emergencies nursing care for generalizing the findings.

\section{Acknowledgements}

The researchers would like to express gratitude and appreciations to the nurses who participated in this study for their effective cooperation.

\section{References}

[1] Alam B., Mridha M. K., Biswas T. K. Roy L., Rahman M., \& Chowdhury M. E. (2015): Coverage of emergency obstetric care and availability of services in public and private health facilities in Bangladesh, Int $\mathrm{J}$ Gynaecol Obstet. doi: 10.1016/j.ijgo.

[2] Alderman J. T. (2012): Using simulation to teach nursing students and licensed clinician's obstetric emergencies, MCN Am J Matern Child Nurs. 37(6): 394-400. doi: 10.1097/NMC.0b013e318264bbe7.

[3] Attia A. M. (2012): Assessment of Emergency nursing care offered at the labor ward of Ain Shams Maternity University Hospital, Master thesis, Faculty of Nursing, Ain Shams University.

[4] The Association of Women's Health, Obstetric and Neonatal Nurses (AWHONN), (2013): Women's Health and Perinatal nursing Care, Quality draft measures specifications, p. 29, available at:

https://www.awhonn.org/awhonn/binary.content.do

[5] Bayley O., Colbourn T., Nambiar B., Costello A., Kachale F., Meguid T. and Mwansambo C. (2013): Knowledge and perceptions of quality of obstetric and newborn care of local health providers: a cross-sectional study in three districts in Malawi, Malawi Med J. 2013 Dec; 25(4): 105-8.

[6] Bhandari T. R. and Dangal G. (2014): Emergency obstetric Care: strategy for reducing maternal mortality in developing countries / vol 9 / no. 1 / issue $17 /$.

[7] Bradley S., Kamwendo F., Chipeta E., Chimwaza W., de Pinho H., and McAuliffe E. (2015): Too few staff, too many patients: a qualitative study of the impact on obstetric care providers and on quality of care in Malawi. BMC Pregnancy Childbirth. Mar 21; 15: 65. doi: 10.1186/s12884-015-04925.

[8] Brenner S., De Allegri M., Gabrysch S., Chinkhumba J., Sarker M., and Muula A. S. (2015): The quality of clinical maternal and neonatal healthcare - a strategy for identifying 'routine care signal functions'. Apr 15; 10(4): e0123968.

[9] Catherin N., Anushila S. R. and Goud B. R. (2014): Obstetric emergencies presenting to a rural community maternity hospital, Southern Karnataka, India, Int, J., curr. Res. Aca. Rev., 2(9) ISSN: 2347-3215 Volume 2 Number 9, pp. 264269.

[10] Chodzaza E, and Bultemeier K. (2010): Service providers' perception of the quality of emergency obstetric care provided and factors identified which affect the provision of quality care, Malawi Med J. 22(4): 104-11.

[11] Delucia P. R., Ott T. E. and Palmieri P. A. (2009): Performance in nursing. In F. Durso (Ed.), Reviews of Human Factors and Ergonomics Society, Vol. 5, pp. 1-40 Santa Monica, CA. 
[12] EL-Bahy M. A., Mohamed H. I., Salam N. S. and Nasr E. H. (2015): Effect of Educational Program for Nurses about Pregnancy Induced Hypertension on their Knowledge in Port Said Hospitals, Med. J. Cairo Univ., Vol. 81, No. 2, March: 179-188, available at: www.medicaljournalofcairouniversity.com.

[13] Gibbs R. S., Karlan B. Y., Haney A. F. \& Nygaard I., (2012): Danforth`s Obstetrics and Gynecology, 10th ed., Lippincott Williams \& Wilkins, China, p. 475.

[14] Islam F., Rahman A., Abdul Halim, Eriksson C., Rahman F. and Dalal K. (2015): Perceptions of health care providers and patients on quality of care in maternal and neonatal health in fourteen Bangladesh government healthcare facilities: a mixed-method study, BMC Health Services Research, 15: 237.

[15] Kavitha P., Tesfay A., Prasath R., Habtegiorgis L., Girmay S., and Sereke Y. (2014): To assess level of knowledge of staff nurses on emergency obstetric management at orotta national referral maternity hospital, Int. J. of Allied Med. Sci. and Clin. Research Vol-2(4) pp. 287-293.

[16] King S. and Scrutton M. (2010): Anesthesia and Intensive Care Medicine 2nd ed., Elsevier, London, PP. 179-188.

[17] Munnur U., Bandi V and Guntupalli K. K., (2011): Management principles of the critically ill obstetric patient, Clin Chest Med. 2011 Mar; 32(1): 53-60, available at: http://www.ncbi.nlm.nih.gov/pubmed/21277449
[18] Ominyi, J N and Nwodom, M U (2014): Nurses' Perception and Practice of Evidence-Based Practice in Federal Teaching Hospital Abakaliki JMSCR Volume 2 Issue 11 Page 27782795.

[19] Otolorin E., Gomez P., Currie S., Thapa K., and Dao B. (2015): Essential basic and emergency obstetric and newborn care: From education and training to service delivery and quality of careInt J Gynaecol Obstet.

[20] Royal College of obstetricians and Gynaecologists guidelines, 2016. Available at https://www.rcog.org.uk/guidelines

[21] The world fact book, 2015, Available at https://www.cia.gov/library/publications/the-worldfactbook/geos/eg.html accessed on September/10/2016

[22] Traoré M., Arsenault C., Schoemaker-Marcotte C., Coulibaly A., Huchon C., Dumont A. ndFournier P., (2014): Obstetric competence among primary healthcare workers in Mali, Int J Gynaecol Obstet. http://www.ncbi.nlm.nih.gov/pubmed/24800658; 126(1): 5055

[23] World health organization, (2013): The world fact Book. Retrived from http://www.cia.gov/library/publications/theworldfactbook/geos/GH accessed on august/21/2016.

[24] WHO, Media centre, Fact sheet, Updated November 2016, Available at http://www.who.int/mediacentre/factsheets/fs348/en/ 